\title{
İslam Ülkeleri İstatistiksel, Ekonomik ve Sosyal Araştırma ve Eğitim Merkezi (SESRTCIC) ${ }^{*}$ Kütüphanesi
}

\author{
Statistical, Economic and Social Research and Training Centre \\ for Islamic Countries (SESRTCIC) Library
}

\section{Z. Canan DURAN ${ }^{* *}$}

\begin{abstract}
Öz
Bu makalede, SESRTCIC Kütüphanesi'nin kuruluşu, gelişimi ve verdiği hizmetler hakkında bilgi verilmektedir.
\end{abstract}

Anahtar sözcükler: SESRTCIC Kütüphanesi, Araştırma kütüphaneleri, Özel kütüphaneler, Ekonomi kütüphaneleri, Kütüphane tanıtımı, Kütüphane hizmetleri.

\begin{abstract}
The present paper informs in detail the foundation and development of the SESRTCIC Library, together with a thorough explanation of the nature of services being provided.
\end{abstract}

Keywords: SESRTCIC Library, Research libraries, Special libraries, Economic libraries, Library publicity, Library services.

\section{Giriş}

İslam Konferansı Örgütü (IKÖ), 57 ülkeden ${ }^{* \star *}$ oluşan ve geniş bir coğrafyaya yayılmış uluslararası bir kuruluştur. İslam Ülkeleri İstatistiksel, Ekonomik ve Sosyal Araşıtırma ve Eğitim Merkezi (SESRTCIC), diğer adıyla Ankara Merkezi, 8. Dışişleri Bakanları Toplantısı'nda (ICFM) ${ }^{1}$ (1977, s. 291) alınan kararla kurulmuştur. İslam Ülkeleri için istatistiksel, ekonomik ve sosyal konularda araştırma ve eğitim faaliyetlerini yürütmek üzere kurulmuş bulunan SESRTCIC'in yerinin Ankara olması; Dışişleri Bakanlığının 27 Aralık 1977

\footnotetext{
* SESRTCIC Web adresi: http://www.sesrtcic.org.

** Kütüphane Sorumlusu; SESRTCIC Attar Sok. No:4 GOP 06700 Ankara (library@sesrtcic.org).

${ }^{* * *}$ iKÖ ülkeleri için bkz. http://www.sesrtcic.org/oic/oicaccda.shtml.

1 ICFM (Islamic Conference of Foreign Ministers): 8. ICFM ToplantısI, 16-22 MayIS 1977, Tripo-

li, Libya, Resolution no. 2/8-E.
} 
tarihli ve IEIG-IETD-5599 sayılı yazıSı üzerine, 31 Mayıs 1963 tarih ve 244 sayılı Kanunun 3. Maddesine göre Bakanlar Kurulunca 28 Aralık 1977 tarihinde kararlaştırılmış (Bakanlar Kurulu Kararı, 7/14549, 1978) ve Ankara Merkezi, 1 Haziran 1978 tarihinde faaliyetine başlamıştır.

IKÖ bünyesinde bulunan altı yan kuruluştan (subsidiary organ) birisi olan SESRTCIC'in amaçlarını şöyle sıralayabiliriz:

> Üye ülkeler hakkında sosyo-ekonomik istatistiksel bilgileri derleyip, düzenlemek ve kullanıma sunmak,

> Üye ülkeler arasında teknik ve ekonomik işbirliğini başlatacak ve geliştirecek çalışmalarda bulunmak,

$>$ Üye ülkelerin gereksinim duyduğu konularda seminer ve eğitim programları düzenlemektir (Sesrtcic.org, 2005a).

\section{SESRTCIC Kütüphanesi}

SESRTCIC Kütüphane ve Dokümantasyon Birimi, İstatistik ve Enformasyon Daire Başkanlığına bağlı SESRTCIC binası içinde hizmet veren özel amaçlı bir araştırma kütüphanesidir. İÖ’ye bağlı üye ülkelerin sosyo-ekonomik yapısının araştırılmasına yönelik bir bilgi bankası kurma görevini üstlenmiş bulunan SESRTCIC'de, kütüphanenin en temel sorumluluğu, bu yönde gereksinim duyulan bilgi kaynaklarını derleyerek, bunları düzenlemek ve hizmete sunmaktır. Ayrıca, 18 Şubat 1987 tarihinde Dünya Bankası ve SESRTCIC arasında yapılan anlaşma gereği Kütüphane, Dünya Bankası'nın Derleme Kütüphanesi (depository library) olma özelliğine sahiptir.

Bir profesyonel kütüphanecinin çalıştığı SESRTCIC Kütüphanesinde, kullanıcılar; SESRTCIC çalışanları ve dışarıdan gelen okuyuculardır. Ekonomistler, istatistikçiler ve çevirmenler kurum çalışanlarını oluşturmaktadır. Kurum dışı okuyucuların çoğunluğunu ise; öğretim üyeleri, üniversite öğrencileri ve araştırmacılar oluşturmaktadır.

\section{Derme}

Kütüphane dermesi, IKÖ ülkelerinin sosyo-ekonomik yapılanmaları ve gelişimleri konusunda yoğunlaşmaktadır. Derlenen bilgiler, üye ülkeler arasında ekonomik işbirliği, üye ülkelerin temel sosyo-ekonomik, istatistik göstergeleri ve güncel ekonomik gelişmeleriyle ilgili konulardadır.

2005 Mart ayı itibariyle kütüphanenin bugünkü dermesi yaklaşık 14 bin basılı, 310 süreli yayın ve 141 CD-ROM'dan oluşmaktadır. SESRTCIC Kütüphanesi ve Dokümantasyon Merkezini diğer bilgi-belge merkezlerinden ayıran noktalar, dermenin özelliğini temsil etmektedir. Bunlar sırası ile; 
> Dünya Bankası'nın derleme kütüphanesi olma nedeniyle Dünya Bankası yayınlarının tümü kütüphaneye düzenli gelmektedir,

> İKÖ’ye üye ülkelerin İstatistik Enstitüsü ve Merkez Bankalarından gelen çeşitli istatistiksel yayınlar derlenmektedir,

> Ankara Merkezin sürdürdüğü araştırmalar için gerekli olan temel uluslararası istatistiksel kaynaklar toplanmaktadır,

$>$ IKÖ ve IKÖ'ye bağlı birimlerin (Subsidiary Organs², Specialised Institutions ${ }^{3}$, Affiliated Institutions ${ }^{4}$, Standing Committees ${ }^{5}$ ) (Sesrtcic.org, 2005b) yayınları gelmektedir,

> SESRTCIC'in katıldığı, IKÖ bünyesinde yapılan toplantı raporları arşivlenmektedir,

> SESRTCIC tarafından IKÖ toplantılarında sunulmuş olan araştırma raporları arşivlenmektedir,

> Süreli yayın dermesi, İKÖ ülkelerinin ekonomik ve sosyal yapısı, kalkınma düzeyleri ve dünya ekonomisindeki yeri gibi konulardan oluşmaktadır,

$>$ CD-ROM dermesinde üye ülkelerin ulusal istatistik enstitüleri ve uluslararası istatistik ofislerden gelen veri setleri yer almaktadır.

\section{Sağlama Hizmeti}

SESRTCIC Kütüphanesi bilgi kaynaklarını üç temel yolla sağlamaktadır. Bunlar; satın alma, değişim (exchange) ve ücretsiz/bağıştır. Aşağıda hangi yayınların ne tür yollarla edinildiği belirtilmiştir.

$>$ Dünya Bankası yayınları anlaşma gereği ücretsiz gönderilmektedir.

\footnotetext{
2 Subsidiary Organs: SESRTCIC, IRCICA (Research Centre for Islamic History, Art and Culture), IUT (Islamic University of Technology), ICDT (Islamic Centre for Development of Trade), IFA (Islamic Figh Academy), ISF (Executive Bureau of the Islamic Solitary Fund ve Waqf).

3 Specialised Institutions: IINA (International Islamic News Agency), IDB (Islamic Development Bank), ISESCO (Islamic, Educational, Scientific and Cultural Organisation), ISBO (Islamic States Broadcasting Organisation).

4 Affiliated Institutions: IAIB (International Association of Islamic Banks), ICCI (Islamic Chamber of Commerce and Industry), ICIC (Islamic Committee of the International Crescent), OISA (Organisation of Islamic Shipowners' Association), OICC (Organisation of Islamic Capitals and Cities), SFISG (Sports Federation of Islamic Solidarity Games), World Federation of International Arab-Islamic Schools.

5 Standing Committees: COMCEC (Standing Committee for Economic and Commercial Cooperation), COMIAC (Standing Committee for Information and Cultural Affairs), COMSTECH (Standing Committee for Scientific and Technological Cooperation).

Not: IKÖ organları hakkında daha fazla bilgi için ayrıca bkz. http://www.sesrtcic.org/links.shtml 
> Ulusal istatistiksel kaynaklar $\mathrm{SH}^{\prime}$ 'de alınan karar gereği değişim yoluyla elde edilmektedir. Bu yayınların kurumlar tarafından düzenli gönderilmesi, 6 ayda bir eksik yayınlar için hatırlatma mektubu gönderilerek sağlanmaktadır.

> Uluslararası istatistiksel yayınların bir kısmı değişim, bir kısmı ise satın alma yoluyla elde edilmektedir.

> IKÖ’ye bağlı örgütlerin yayınları değişim yoluyla sağlanmaktadır.

> Kitaplar ve başvuru kaynakları bağış ve satın alma yoluyla kütüphaneye kazandırılmaktadır.

> Süreli yayınlar değişim, satın alma ve bağış yoluyla elde edilmektedir.

\section{Kataloglama ve Sınıflama}

Kütüphanede, Ankara Merkez'in bilgisayar programcıları tarafından geliştirilmiş olan LIS (Library Information System) programı kullanılmaktadır. Sınıflama sistemi de; otomasyon programı gibi SESRTCIC tarafından geliştirilen; kullanıcıların rahatça istediğini bulabilmesine yönelik oluşturulmuş bir sistemdir. Kütüphane dermesi konu sınıflaması yerine, kurum içi kullanım biçimlerine göre; yani, bilgi kaynaklarının kodlanması; sınıflandırma amacından çok, adresleme, sürekli ve hızlı bilgi akımının sağlanması temel alınarak yapılandırılmıştır. Bilgi kaynakları şu şekilde düzenlenmektedir.

$>$ Kitaplar konularına,

$>$ Danışma kaynakları türlerine,

$>$ Dünya Bankası yayınları seri bilgilerine,

> Ulusal istatistiksel kaynaklar ülke kodları ve konularına; uluslararası istatistiksel kaynaklar kurum numarasına,

> SESRTCIC ve İKÖ belgeleri teknik ve idari olma özelliklerine göre; belge türü, belgenin sunulduğu toplantı, tarih ve hangi dilde sunulduğu bilgileri temel alınarak kütüphane tarafından geliştirilen bir kodlama yöntemine göre düzenlenmektedir.

\section{Kütüphane Programı}

LIS (Library Information System) dört veri tabanından oluşmaktadır. Bu veri tabanları ve kapsadıkları bilgi kaynakları aşağıdaki gibidir:

> Kütüphane: Kitaplar, danışma kaynakları, istatistiksel yayınlar, Dünya Bankası yayınları, ve uluslararası kuruluşlardan gelen yayınların bibliyografik künyeleri bulunmaktadır. 
> Makale: Süreli yayın dermesi içindeki dergiler arasından Ankara Merkezi ilgilendiren konularda seçilen makalelerin bibliyografik künyelerini ve özlerini kapsamaktadır.

> Süreli Yayınlar: Kütüphaneye gelen süreli yayınların kayıtları tutulmaktadır.

> Belgeler: SESRTCIC raporlarının bibliyografik künyelerini içermektedir.

2003 tarihinde Merkezin 25. Yıl kutlamaları çerçevesinde Bilgisayar Bölümü LIS'e ait web modülü geliştirmiş; kitaplar ve Dünya Bankası yayınlarının bir bölümü internet üzerinden çevrimiçi katalog aracılığı ile taranabilir duruma getirilmiştir.

\section{Okuyucu Hizmetleri}

Kurum içi ve dışı tüm okuyucuların bilgi ihtiyaçlarının karşılanmasının yanında, kütüphaneye gelen yeni yayınlar "güncel duyuru hizmeti" adı altında SESRTCIC araştırmacılarına duyurulmaktadır. Bu hizmet iki şekilde yapılmaktadır; ilki, kütüphaneye gelen yeni yayınların bibliyografik künyeleri Ankara Merkezin üç ayda bir çıkardığı InfoReport7’ta ve SESRTCIC Web sayfasında (Library/New Arrivals) ${ }^{8}$, diğeri ise; hakemli olan süreli yayınlar içinden üye ülkeler ile ilgili olan makaleler seçilmekte ve makalelerin bibliyografik künyeleri ve özleri Journal of Economic Cooperation among Islamic Countries (JEC) 9'de "Selected Abstracts from SESRTCIC's Articles Database" bölümünde yayınlanmaktadır.

\section{Ödünç Verme Hizmeti}

Kütüphane, kurum içi çalışanlara herhangi bir sınırlama getirmeden ödünç verme hizmeti sunmaktadır. Dışardan gelen okuyucular bu hizmetten yararlanamamaktadır; ancak, kendilerine fotokopi hizmeti verilmektedir.

\section{SESRTCIC Yayınları ve Kütüphane}

Bir araştırma merkezi olarak SESRTCIC yayınlarını beş grupta toplayabiliriz. Bunlar; istatistiksel yayınlar, danışma kaynakları, kitaplar, süreli yayınlar ve raporlardır. Düzenli yayınlanan eserler şunlardır;

\footnotetext{
6 SH (The Meeting of the Heads of National Statistical Organizations): IKÖ Ülkeleri Ulusal İstatistik Organizasyonları Başkanları Toplantısı (SESRTCIC, 1998, s. 143).

7 InfoReport: SESRTCIC bülteni, yılda 4 sayı olarak, Ingilizce, Fransızca ve Arapça yayınlanır.

8 Library/New Arrivals: http://www.sesrtcic.org/library/seslibacq.shtml

9 Journal of Economic Cooperation among Islamic Countries (JEC): SESRTCIC tarafından ÇIkarılan yılda 4 sayı olarak yayınlanan Ingilizce dergidir.
} 
> Statistical Yearbook of the OIC Member Countries (Yıllık; Arapça ve Ingilizce-Fransızca yayınlanmaktadır).

$>$ Training Opportunities in OIC Countries (Yıllık; Arapça, İngilizce ve Fransızca yayınlanmaktadır).

- Journal of Economic Cooperation among Islamic Countries (JEC) (Yılda 4 sayı olarak İngilizce yayınlanmaktadır. Ayrıca yılda bir sayı yapan Arapça basımı bulunmaktadır).

> InfoReport (Yılda 4 sayı olarak Arapça, İngilizce ve Fransızca yayınlanmaktadır).

Kütüphanenin SESRTCIC yayınları ile ilgili sorumlulukları aşağıda sıralanmıştır;

> "Statistical Yearbook of the OIC Member Countries" in bibliyografyasını hazırlamak,

> JEC için "Selected Abstracts from SESRTCIC's Articles Database" bölümünü oluşturmak,

> InfoReport için "Ankara Centre Publications" ve "What's New in the Centre Library" bölümlerini hazırlamak,

> Yeni çıkacak SESRTCIC yayınlarının ISBN ve ISSN'leri için Kütüphaneler Genel Müdürlüğü ile gerekli yazışmaları yapmak,

> SESRTCIC yayınları için dışardan gelen sipariş işlemlerini izlemek,

> JEC'in e-kopyalarının10 e-posta yoluyla düzenli bir şekilde EBSCO Yayın Bölümüne (EBSCO Publishing Departmant) PDF formatında göndermek olarak sıralanabilir.

\section{Web Sayfası}

SESRTCIC Web sitesinde sık ziyaret edilen bölümlerden biri de Kütüphane ${ }^{11}$ dir. Kütüphane bölümünde genel bilgiler, çevrimiçi katalog ve yeni gelen yayınların bibliyografik künyeleri bulunmaktadır.

Web sitesinde aşağıda sıralanan sayfalar InfoReport'un çıkış tarihlerinde (her yılın Ocak, Nisan, Temmuz ve Ekim aylarında) düzenli güncellenmektedir.

$>$ Kütüphane/Yeni Gelenler (Library/New Arrivals),

$>$ Yayın Bölümü/Sipariş (Publication/Ordering SESRTCIC Publications),

> Yayın Bölümü/Son SESRTCIC Yayınları (Publication/Latest SESRTClC Publications),

$>$ İstatistik Bölümü/Kaynaklar (Statistics/Sources).

\footnotetext{
102 Temmuz 2002 tarihinde EBSCO ve SESRTCIC arasında yapılan anlaşma gereği JEC EBSCO veri tabanında yer almaktadır.

11 http://www.sesrtcic.org/library/default.shtm/
} 


\section{Sonuç}

SESRTCIC Kütüphane ve Dokümantasyon Merkezi öncelikle İKÖ ülkelerinin istatistik ve ekonomik durumları konusunda kaynakları derleyen, bunları hizmete sunan ve bu konularda yayın üretilmesinde katkıda bulunan Türkiye'deki tek dokümantasyon merkezidir. Ayrıca Dünya Bankası'nın derleme kütüphanesi olmasından dolayı Dünya Bankası'nın en güncel yayınları kütüphanede okuyuculara sunulmaktadır. Bu iki önemli özelliğinin yanında SESRTCIC Kütüphane ve Dokümantasyon Merkezi okuyucularına daha iyi hizmet verebilmek için çalışmalarına devam etmektedir; bunlar arasında, kütüphane dermesini zenginleştirme ve çeşitlendirme; MARC uyumlu bir otomasyon programının uygulamaya konması projelerini sıralayabiliriz. Otomasyon programı projesi gerçekleştiğinde kütüphanede bulunan tüm bilgi kaynaklarının Internet üzerinden çevrimiçi katalog aracılığı ile bibliyografik künyelerinin taranabilir duruma gelmesi, hatta makale veri tabanı aracılığı ile makalelerin özlerine de ulaşma imkanı sağlanacaktır. Bu durum SESRTCIC Kütüphane ve Dokümantasyon Merkezinin İslam Konferansı Örgütü organları arasında bilgi hizmeti sunma konusunda, yerini olumlu anlamda farklı kılacaktır.

\section{Kaynakça}

Bakanlar Kurulu Kararı 7/14549 (1978, 7 Ocak). Resmi Gazete, 16162.

Islamic Conference of Foreign Ministers (16-22 Mayıs 1977). Resolution on the Establishment of a Statistical, Economic and Social Research and Training Centre for the Islamic Countries (Resolution No: 2/8-E). Tripoli, Libya: ICFM.

SESRTCIC (1998). Report of the 3rd Meeting of the Heads of the National Statistical Organisations of the member states of the Organisation of the Islamic Conference. Papers and Procedings of the 3rd Meeting of the Heads of the National Statistical Organisations of the Member States of the OIC: 1-3 June 1998, Ankara, Turkey raporu içinde (ss. 115-123). Ankara: SESRTCIC.

Sesrtcic.org (2005a). 8 Mart 2005 tarihinde http://www.sesrtcic.org/ adresinden erişildi.

Sesrtcic.org (2005b). 8 Mart 2005 tarihinde http://www.sesrtcic.org/oic/ oicorgan.shtml adresinden erişildi. 